Article

\title{
Increasing Impact Strength of a Short Glass Fiber Compression Molded BMC by Shortening Fibers without Change in Equipment
}

\author{
Michael C. Faudree ${ }^{1, *(\mathbb{D})}$, Yoshitake Nishi ${ }^{2,3}$ and Michelle Salvia ${ }^{4}$ \\ 1 Faculty of Liberal Arts and Science, Tokyo City University, Yokohama-shi 224-8551, Japan \\ 2 Graduate School of Engineering, Tokai University, Hiratsuka-shi 259-1292, Japan; west@tsc.u-tokai.ac.jp \\ 3 Kanagawa Institute of Industrial Science and Technology (KISTEC), Ebina-shi 243-0435, Japan \\ 4 Ecole Centrale de Lyon, Ecully, CEDEX, 69134 Lyon, France; michelle.salvia@ec-lyon.fr \\ * Correspondence: faudree@tcu.ac.jp; Tel.: +81-(0)45-910-0104 (ext. 2906)
}

Citation: Faudree, M.C.; Nishi, Y.; Salvia, M. Increasing Impact Strength of a Short Glass Fiber Compression Molded BMC by Shortening Fibers without Change in Equipment.

Materials 2022, 15, 1145.

https://doi.org/10.3390/ma15031145

Academic Editors: Valentina Medri and Roberts Joffe

Received: 17 October 2021

Accepted: 25 January 2022

Published: 1 February 2022

Publisher's Note: MDPI stays neutral with regard to jurisdictional claims in published maps and institutional affiliations.

Copyright: (c) 2022 by the authors. Licensee MDPI, Basel, Switzerland. This article is an open access article distributed under the terms and conditions of the Creative Commons Attribution (CC BY) license (https:// creativecommons.org/licenses/by/ $4.0 /)$.

\begin{abstract}
Bird strike, volcanic rock, hailstones, micrometeoroids, or space debris can cause damage to aircraft and space vehicles, therefore their composite materials must have high impact resistance to maximize safety. In a $55 \%$ wt. $\mathrm{CaCO}_{3}$ compression molded short glass fiber polyester GFRPBMC (bulk molded compound), shortening the nominal $6.4 \mathrm{~mm}$ fiber length formulation, by $30 \mathrm{~min}$ extended mixing, to $0.44 \mathrm{~mm}$ was found to increase Charpy impact values, $a_{\mathrm{uc}}$, without a change in the compression molding equipment. Specimens were cut from square panels in a spiral configuration in conformity with ASTM D 6110-02 for orthotropic panels, the flow direction approximately radially outward from the charge. At a median-fracture probability of $P_{\mathrm{f}}=0.50$, extended mixing improved $a_{\mathrm{uc}}$ by $29 \%$, from 7.43 to $9.59 \mathrm{kJm}^{-2}$, and for each solidification texture angle, namely, 0 to 90 (random), 71,45 and $18 \mathrm{deg}$, the $a_{\mathrm{uc}}$ increased by $25 \%$ ( 6.26 to $\left.7.86 \mathrm{kJm}^{-2}\right), 18 \%\left(9.36\right.$ to $\left.11.07 \mathrm{kJm}^{-2}\right), 35 \%(7.68$ to $\left.10.37 \mathrm{kJm}^{-2}\right)$, and $20 \%$ (6.96 to $8.36 \mathrm{kJm}^{-2}$ ), respectively. This strengthening can be explained by an increased number of thermal compressive stress sites between the glass fiber and matrix due to a difference in the coefficient of thermal expansion (CTE) during cool-down, and shrinkage, with an increased number of spaces between fibers, $\left|S_{\mathrm{f}}\right|$ from 217 to approximately 2950 per $\mathrm{mm}^{3}$, enhancing impact energy.
\end{abstract}

Keywords: bulk molding compound; polyester; glass fibers; Charpy impact; solidification texture angle

\section{Introduction}

Bulk molded compounds (BMCs) are utilized for non-heavy load bearing parts, having advantages over metals in being lightweight, lowering fuel consumption for aircraft and other vehicles to reduce $\mathrm{CO}_{2}$ emissions, and are also corrosion resistant. BMCs typically contain $\sim 5$ to $30 \mathrm{wt}$.\% fiber and are highly filled [1-10]. Glass fiber reinforced polymer GFRP-BMCs contain $\sim 5$ to 30 mass\% chopped fiber about 3 to $13 \mathrm{~mm}$ in length $[1,3,7]$, and are highly filled with $\mathrm{CaCO}_{3}$ powder ranging from $\sim 35$ to over 50 mass $\%[7,8]$, while other fillers can include $\mathrm{TiO}_{2}, \mathrm{Al}_{2} \mathrm{O}_{3}, \mathrm{SiC}, \mathrm{Mg}(\mathrm{OH})_{2}, \mathrm{ZnO}$, [9] fumed silica [10], fly ash [5], or waste thermosetting BMC [2], to name a few [1-10].

Previously, unexpected findings for FRP composites, namely that of polyester with styrene-butadiene copolymer reinforced with glass fibers and $\mathrm{CaCO}_{3}$ filler, were reported where the tensile modulus could be increased by 5 to $25 \%$ [8] along with fracture strength, and its strain increased $\sim 60$ and $\sim 40 \%$ [7], by decreasing mean fiber length from the commercial $6.4 \mathrm{~mm}(1 / 4 \mathrm{in})$ to $0.44 \mathrm{~mm}$ via $30 \mathrm{~min}$ of extended mixing of paste prior to injection molding, without a change in the injection molding equipment. This was a new finding not observed prior, because most of the literature concerns 2-phase fiber and polymer composites whose mechanical properties, such as impact strength, tensile stress and strain, increase with increasing fiber length [11-17], and longer fibers are reported as desired [18]. However, the GFRP-BMC is a 3-phase filler, fiber and polymer system in 
which the $\mathrm{CaCO}_{3}$ filler particles appear to play a role in strengthening the composite when shortening the fiber length below that of commercial length $[7,8]$. Therefore, this study presents new experimental results that impact strength and can be increased by a $30 \mathrm{~min}$ extended mixing in the GFRP-BMC.

The strengthening method is congruent to earlier studies [7,8] of 30 min extended mixture of commercial $6.4 \mathrm{~mm}$ fiber length GFRP-BMC paste to shorten glass fibers to $0.44 \mathrm{~mm}$, prior to injection molding [7]. Nominal fiber length of $6.4 \mathrm{~mm}$ was chosen since it was commercially available, whereas the $0.44 \mathrm{~mm}$ length was produced by $30 \mathrm{~min}$ of mixing [2]. The $0.44 \mathrm{~mm}$ fiber length was determined by measuring several hundred fibers of polished masticated samples by SEM, showing a mean fiber length of $0.44 \mathrm{~mm}$ (standard deviation $= \pm 0.203 \mathrm{~mm})[1,7]$. Generally, two standard deviations equal about $95 \%$ of the population $\left(0.04 \mathrm{~mm}<l_{\text {fiber }}<0.85 \mathrm{~mm}\right)$, representing a wide distribution from the extended mixing, yet significantly less than $6.4 \mathrm{~mm}[1,7]$, and below the reported critical fiber length for GFRPs of $\sim 1.0 \mathrm{~mm}(0.56-0.59 \mathrm{~mm}$ for nylon GFRP; $1.4 \mathrm{~mm}$ for polypropylene (PP) GFRP; and 0.68 to $0.84 \mathrm{~mm}$ for polybutylene terephthalate (PBI) GFRP) [14]; however these critical lengths are for 2-phase systems $[14,15]$ and would depend on the strength of the coupling. Nevertheless, the glass fibers have a strong coupling agent to adhere to the polymer component in the GFRP-BMC. Therefore, mean fiber lengths of the 6.4 and $0.44 \mathrm{~mm}$ data sets are considered to have enough variance for the results to be reliable $[7,8]$. With a 30 min extended mix, it is assumed, in the compression molded samples, that fiber length is reduced to approximately $0.44 \mathrm{~mm}$. The $\mathrm{CaCO}_{3}$ filler $(<1$ to $\sim 7 \mu \mathrm{m})$ is reported to be unaffected by 30 min extended mixing [2].

The polymers used in the formulation are thermoset polyester, with styrene-butadiene, as illustrated in Figure 1.<smiles>O=C(O)CCCC(=O)OCC(O)CO</smiles>

(a)

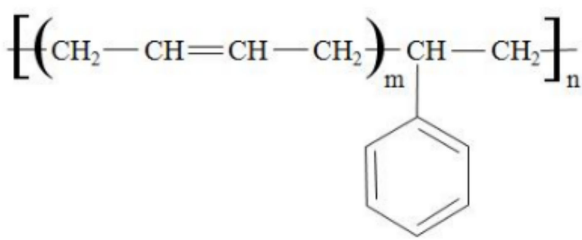

(b)

Figure 1. Rational formulae of (a) thermoset polyester, and (b) styrene butadiene.

To provide background, fiber length studies on polymer composites appear to be predominantly limited to 2-phase fiber and polymer systems, where mechanical properties are reduced with shortened fibers $[11-17,19,20]$. In a study of polypropylene GFRP at a fiber weight percent between 3 and $60 \%$, varying fiber length from 0.1 to $50 \mathrm{~mm}$ showed that stiffness was reduced at fiber lengths under $0.5 \mathrm{~mm}$, and was nearly unaffected above $0.5 \mathrm{~mm}$ [11]. High weight percentages above $40 \%$ were reported to cause fiber packing problems, with an increase in void formation reducing the modulus [11]. It was also reported for polypropylene GFRP, that impact properties were raised as fiber length was increased to $6.4 \mathrm{~mm}$, while a strain energy model predicted $8 \mathrm{~mm}$ as the optimal fiber length [13]. For short carbon fiber polypropylene CFRP, Izod impact, Rockwell hardness, tensile strength and modulus, and flexural strength and modulus values were lowered as fiber lengths were shortened: $10 \rightarrow 5 \rightarrow 2 \rightarrow 1 \rightarrow 0.5 \mathrm{~mm}$ [17]. Similarly, Capela et al. found in compression molded CFRP with Biresin ${ }^{\circledR} \mathrm{CR} 120$ resin, for higher $V_{\mathrm{f}}$ of $60 \mathrm{wt}$ \% carbon fibers, the optimum fiber length for tensile properties was $4 \mathrm{~mm}$. Stiffness and tensile strength increased by increasing fiber length from $2 \mathrm{~mm}$ to $4 \mathrm{~mm}$, but then decreased for $6.4 \mathrm{~mm}$ fibers. The decrease was attributed to poor fiber dispersion, and disorder within the matrix with the longer fibers [19].

In addition, a trend of decreasing mechanical properties with shorter fiber length has been found for green composites (2-phase). In hemp fiber reinforced thermoplastic 
polyurethane, increasing the fiber length from 6 to an optimum of $15 \mathrm{~mm}$ increased tensile strength from 16 to $27 \mathrm{MPa}$, while a further increase to $40 \mathrm{~mm}$ resulted in little change [20].

Because assessing the effect of fiber length can be difficult, many studies on 2-phase GFRP systems have utilized numerical modelling to characterize the increase in mechanical properties as fibers are lengthened, predicting that shortening fibers below the critical length of $\sim 1.0 \mathrm{~mm}$ greatly reduces mechanical properties [14,15].

Conversely, we demonstrate a new result not previously reported in the literature, that for the highly-filled 3-phase GFRP-BMC, impact values can be increased by shortening fibers below $1.0 \mathrm{~mm}$. The strengthening mechanism is similar to ceramics, cemented carbide composites, and metal matrix composites (MMC), in that strength is increased by decreasing the particle size [21-23]. For instance, in WC-Ni cemented carbide composites, strength was increased for $0.5 \mu \mathrm{m}$ particles above the coarser $1.7 \mu \mathrm{m}$ particles [21]. $\mathrm{In}_{\mathrm{Al}_{2} \mathrm{O}_{3}}$ dispersed ceramics, the smaller $16 \mu \mathrm{m}$ diameter particle size raised fracture stress $30 \%$ above $41 \mu \mathrm{m}$ diameter particle size [22]. The enhancements were attributed to the difference in the proliferation of residual stress sites by CTE (coefficient of thermal expansion) between particles and matrix, as particle size was reduced. Reported SEM observations for injection molded polyester GFRP-BMC showed $\mathrm{CaCO}_{3}$ filler particles to be $<1$ to $7 \mu \mathrm{m}$ [8], about the same size as reported for ceramics, namely, from $<1 \mu \mathrm{m}$ to several microns [21-23].

As for the effect of percent filler on BMC, few studies were found. One study was performed with polymer mixed with a filler of waste thermosetting BMC (filler, glass fiber and polymer) crushed into a powder, where filler amounts of $0 \rightarrow 30 \rightarrow 40 \rightarrow 50 \rightarrow 60 \mathrm{wt}$.\% resulted in fairly low impact values of $4.91 \rightarrow 1.76 \rightarrow 1.69 \rightarrow 1.73 \rightarrow$ and $1.93 \mathrm{kJm}^{-2}$, respectively [2]. Shore D hardness was virtually unchanged at $\sim 66^{\circ}$ Sh D [2]. Loss of properties were attributed to poor adhesion between filler and matrix. Since our study focuses on fiber length, the effect of percent filler will not be covered here.

For 3-phase GFRP-BMCs, decreasing mechanical properties with decreasing fiber length has been reported [3]. In a highly filled 50 wt. $\% \mathrm{CaCO}_{3}$ GFRP-BMC with 30 wt.\% polymers and 16.7 wt.\% glass fibers, bending strength and modulus were reported to decrease with glass fiber length. For $12.7 \rightarrow 6.4 \rightarrow 3.2 \mathrm{~mm}(1 / 2 \rightarrow 1 / 4 \rightarrow 1 / 8$ in) fibers, bending strength decreased: $115 \rightarrow 81 \rightarrow 53 \mathrm{MPa}$, along with bending moduli: $13.4 \rightarrow 12.3 \rightarrow 11.5 \mathrm{GPa}$ [3]. This indicates that choice of binder and other additives are important for good adhesion of matrix with filler and fibers in GFRP-BMCs.

In our study, the CTE of cured polyester resin matrix (55 to $\left.100 \times 10^{-6} / \mathrm{K}\right)$ [24] is approximately ten times higher than E-glass fibers $\left(5.4 \times 10^{-6} / \mathrm{K}\right)$ [25], hence, when the panels are cooled, the matrix will volumetrically contract onto the fibers more than the fibers contract themselves, creating compressive residual stresses onto the fibers. It follows that shorter fiber length creates a higher number of spaces between fibers $\left(S_{\mathrm{f}},{ }\right)$ [8] allowing increased sites for action of CTE difference to collectively stiffen the composite, thereby raising impact strength.

In fact, tensile tests of GFRP-BMC showed that shortening glass fibers: $6.4 \rightarrow 3.2 \rightarrow 0.44 \mathrm{~mm}$ increased stiffness in the form of initial tensile modulus ( $\mathrm{d} \sigma / \mathrm{d} \varepsilon)_{\mathrm{o}}$ (strain, $\varepsilon=0$ to $0.05 \%$ ) with decreasing fiber length of $6.19 \rightarrow 7.18 \rightarrow 7.86 \mathrm{GPa}$ [8]. Maximum moduli $(\mathrm{d} \sigma / \mathrm{d} \varepsilon)_{\max }$ between the zero point and $\Delta \varepsilon=0.4 \%$ were also increased: $7.50 \rightarrow 8.86 \rightarrow 9.54 \mathrm{GPa}$ for the $6.4 \rightarrow 3.2 \rightarrow$ and $0.44 \mathrm{~mm}$ samples, respectively. In sum, shorter $0.44 \mathrm{~mm}$ samples exhibited a $27 \%$ and $40 \%$ increase in $(\mathrm{d} \sigma / \mathrm{d} \varepsilon)_{\mathrm{o}}$ and $(\mathrm{d} \sigma / \mathrm{d} \varepsilon)_{\max }$, respectively, over those of commercial $6.4 \mathrm{~mm}$ [8]. An increase in modulus with lowering fiber length was attributed to increasing spaces between fibers acting with a CTE difference as mentioned above [8]. Interestingly, the $0.44 \mathrm{~mm}$ samples appeared to show evidence of slight strain hardening during early tensile deformation. Although an earlier study of the data showed little change in modulus with decreasing fiber length [7], when analyzed in more detail at strain increments $\Delta \varepsilon=0.00734 \%$, the increase was found [8].

As for higher deformations with increasing damage, tensile stress-strain curves of the GFRP-BMC exhibited $\sim 60$ and $-40 \%$ increase in tensile fracture stress and strain, respectively, by shortening fibers from a commercial length of $6.4 \mathrm{~mm}$, to $0.44 \mathrm{~mm}$ [7]. 
Acoustic emission (AE) detected three times the number of cracks, while scanning electron microscopy (SEM) showed increased fiber debonding at fiber ends and along fiber lengths in the $0.44 \mathrm{~mm}$ samples compared with the $6.4 \mathrm{~mm}$ sample. Increases in tensile properties were attributed to strain fields from the fiber debonding proliferating expansion sites, which have been found to halt cracks before their critical length is reached [7]. However, damage from impact occurs much faster than tensile tests, therefore, it would seem the cracking dynamics of sudden impact would differ from that of tensile. It follows that the stress-strain curves showed a higher modulus at all strains throughout tensile deformation up to fracture [7], therefore, an increase in impact resistance seems mostly due to increased stiffness, and less to expansion around fibers caused by debonding. Moreover, since the impact tip hitting the specimen is a straight line across the specimen thickness, a higher number of fibers would be directly impacted in the higher-dispersed $0.44 \mathrm{~mm}$ samples, in which hardness is more evenly distributed. Therefore, the main mechanism of increasing impact resistance in the GFRP-BMC by $30 \mathrm{~min}$ of extended mixing appears be from an increase in stiffness throughout the impact process.

Unlike 2-phase fiber and polymer systems, within the matrix itself, the third phase of $\mathrm{CaCO}_{3}$ particles evidently assists in strengthening [8]. Particles well-dispersed and at short distances from each other can be advantageous in maximizing residual thermal stresses [26] leading to the design of stronger BMC composites. Within spaces between fibers, $S_{\mathrm{f}}$, the filler and polymer sub-system undergoes compressive stresses as a whole, the resin shrinking around $\mathrm{CaCO}_{3}$ filler and fibers, with higher and more dispersed force than 2-phase fiber and polymer systems, increasing-not decreasing-mechanical properties as fiber length is decreased.

To the knowledge of the authors, increasing the impact strength of GFRP-BMC by shortening fibers has not yet been reported. Therefore, the goal is to demonstrate that Charpy impact values can be increased in compression-molded short-fiber GFRP-BMC panels containing a high percentage ( 55 mass $\%$ ) of $\mathrm{CaCO}_{3}$ filler, by shortening fibers from a commercial length of $6.4 \mathrm{~mm}$ to $0.44 \mathrm{~mm}$, by 30 min extended mixing prior to molding, without changing the compression molding equipment.

\section{Materials and Methods}

\subsection{Preparation of GFRP}

The components, molding parameters, and fiber lengths of the GFRP-BMC compression molded panels [27-29] are summarized in Tables 1-3.

Panels were provided by Premix, Inc., (now Citadel) of North Kingsville, Ohio, with nominal $6 \mathrm{~mm}$ to $6.4 \mathrm{~mm}$ chopped glass fibers (exact nominal length between 6 and $6.4 \mathrm{~mm}$ proprietary), reported here as U.S. $1 / 8$ in $(6.4 \mathrm{~mm})[7,27]$. As mentioned above, the mean fiber lengths of the 6.4 and $0.44 \mathrm{~mm}$ data sets are considered to have enough variance for results to be reliable [7,8]. Optical microscope Nikon Eclipse ME600 was used to examine the polished GFRP-BMC samples.

Figure 2 shows Charpy impact samples with dimensions $80 \times 10 \times 2 \mathrm{~mm}$ cut in a spiral formation according to ASTM D 6110-02 (2002) [29], since mold flow in the compression molded GFRP-BMC panels is anisotropic. This resulted in four 7-sample sub-quadrants

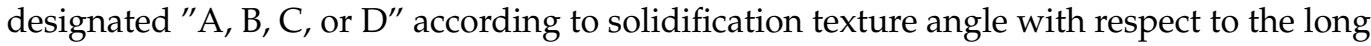
80 mm direction, $\theta_{\mathrm{t}}(\mathrm{deg})$, of: random (45) 0 to 90 ; (71 \pm 7$) ;(45 \pm 10)$; and $(18 \pm \sim 17.5)$ [27,28]. 
Table 1. GFRP-BMC components.

\begin{tabular}{cc}
\hline Component & Mass \% \\
\hline propylene glycol maleate polyester & 13.75 \\
styrene butadiene copolymer & 12.75 \\
commercial E-glass fibers & 11 \\
$\mathrm{CaCO}_{3}$ filler & 55 \\
aluminum silicate filler & 3 \\
magnesium hydroxide & 0.5 \\
proprietary initiators and inhibitors & 4 \\
\hline
\end{tabular}

Table 2. Compression molding parameters.

\begin{tabular}{cc}
\hline Parameter & Condition \\
\hline Mold Pressure & $5.5-6.9 \mathrm{MPa}(800-1000 \mathrm{psi})$ \\
Temperature & $422 \mathrm{~K}\left(149{ }^{\circ} \mathrm{C}\right)$ \\
Cure Time & $2 \mathrm{~min}$ \\
Mold Type & matched metal die compression mold \\
Panel Size & $304.8 \times 304.8 \times 2 \mathrm{~mm}$ \\
$V_{\mathrm{f}}$ (E-glass fibers $)$ & 0.080 \\
$V_{\mathrm{f}}($ CaCO 3 filler $)$ & 0.377 \\
$V_{\mathrm{f}}$ (remaining polymer mixture $)$ & 0.543 \\
\hline
\end{tabular}

Table 3. Fiber lengths.

\begin{tabular}{cc}
\hline Fiber Lengths & Mixing \\
\hline $6.4 \mathrm{~mm}(1 / 8 \mathrm{in})$ & $20 \mathrm{~min}$ \\
$0.44 \mathrm{~mm}[7,8]$ & $20 \mathrm{~min}+$ additional $30 \mathrm{~min}$ \\
\hline
\end{tabular}

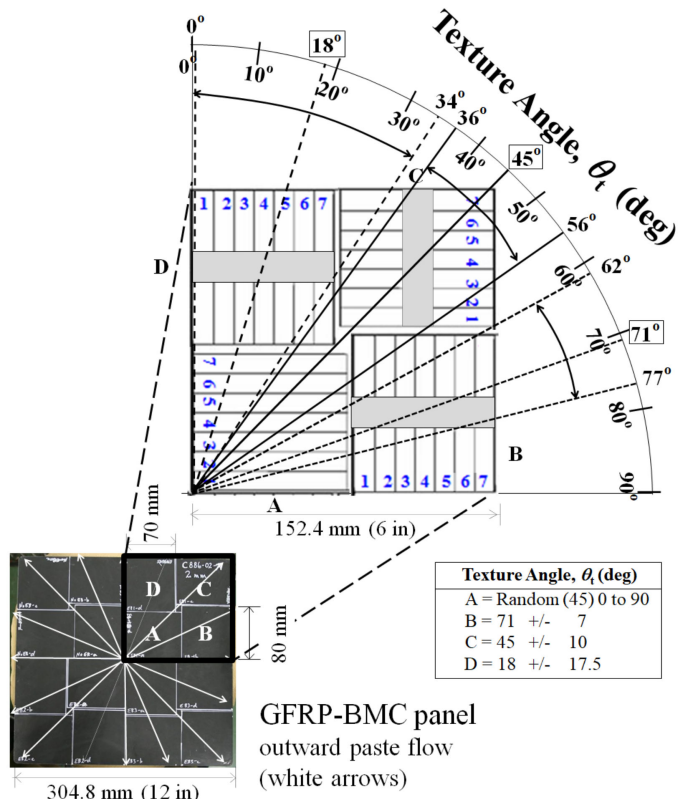

Figure 2. GFRP-BMC panel and specimen cutting configuration according to ASTM D 6110-02, taken from Faudree et al. (2018) [28].

Table 4 shows 56 tested samples of GFRP-BMC for each of the two fiber length sample data sets of 6.4 and $0.44 \mathrm{~mm}$, divided into 14 samples within each section $A, B, C$, and D, respectively. Figure 2 shows the location of the sample in the panel, according to the sample number, which is always counted from center 1 to 7 . These were designated as "A1, A2, 
A3; B1, B2, B3, etc.". Since 2 sub-quadrants of 7 samples each were tested, to distinguish the samples, the second quadrant was designated as " $\mathrm{A} 1^{\prime}, \mathrm{A} 2^{\prime}, \mathrm{A} 3^{\prime}$; $\mathrm{B} 1^{\prime}, \mathrm{B} 2$ ', $\mathrm{B} 3^{\prime}$, etc.", therefore, the same location according to the solidification flow angle can be compared.

Table 4. Number of GFRP-BMC samples tested.

\begin{tabular}{cccccc}
\hline Fiber Length (mm) & $\begin{array}{c}\text { Total } \\
\text { A + B + C + D }\end{array}$ & A & B & C & D \\
\hline 6.4 & 56 & 14 & 14 & 14 & 14 \\
0.44 & 56 & 14 & 14 & 14 & 14 \\
\hline
\end{tabular}

\subsection{Charpy Impact Tests}

Charpy impact tests were conducted to evaluate fracture toughness, $a_{\mathrm{uc}}\left(\mathrm{kJm}^{-2}\right)$, of the GFRP-BMC samples. The Charpy impact test is a quick and easy method often employed to evaluate the safety of materials for quality control (QC). Figure 3 shows the apparatus used (Shimadzu Corp. No. 51735) conforming to JIS K 7077-1991 testing standard, which operated by a drop weight pendulum [27-33]. A diamond cutter (MC-201, MARUTO) was used to cut unnotched specimens to size according to JIS K 7077-1991 [30].

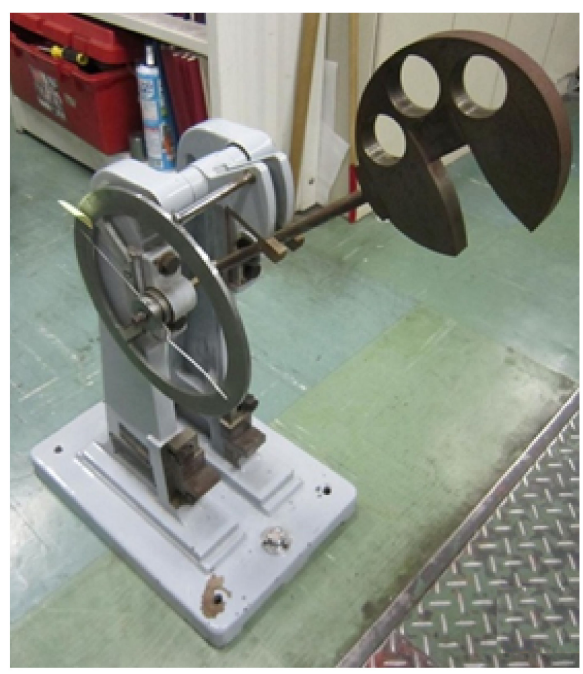

Figure 3. Charpy impact tester.

Impact fracture energy, $\mathrm{E}(\mathrm{kJ})$ is calculated in Equation (1):

$$
E=W R\left[(\cos \beta-\cos \alpha)-\left(\cos \alpha^{\prime}-\cos \alpha\right)(\alpha+\beta) /\left(\alpha-\alpha^{\prime}\right)\right]
$$

where $W$ = hammer mass $(0.86 \mathrm{~kg}), R=$ distance from impact point of specimen to rolling center $(0.21 \mathrm{~m}), \beta=$ finish angle after impact (radians), $\alpha=$ start angle (2.3 radians) and $\alpha^{\prime}=$ average angle of 3 blank tests for calibration $[30,31]$. The $a_{\mathrm{uc}}\left(\mathrm{kJ} / \mathrm{m}^{2}\right)$ is calculated by $[30,31]$ :

$$
a_{\mathrm{uc}}=E /(b t)
$$

where $b=$ sample width $(\sim 10 \mathrm{~mm})$ and $t=$ thickness $(\sim 2 \mathrm{~mm})$. When the specimen was placed in the holder, there was a gap distance of $40 \mathrm{~mm}$. The fracture probability, $P_{\mathrm{f}}$, is expressed using the median rank method [33]:

$$
P_{\mathrm{f}}=(I-0.3) /\left(N_{\mathrm{s}}+0.4\right)
$$

where $N_{\mathrm{S}}$ is the total number of samples $\left(N_{\mathrm{S}}=56\right.$ for each data set; or 14 for each subquadrant, A, B, C, D) and $I$ is the ascending strength order of each sample, respectively. 


\section{Results and Discussion}

3.1. Effect of Shortening Fibers on Impact Strength of Panel at All Texture Angles, $\theta_{t}$ Cumulative, and Sub-Quadrants

Table 5 shows the results for all texture angles, $\theta_{\mathrm{t}}$ cumulative. Shortening fibers from the commercial length of $6.4 \mathrm{~mm}$ to $0.44 \mathrm{~mm}$ raised the average $a_{\mathrm{uc}}$ by $26 \%$ from 7.63 to $9.62 \mathrm{kJm}^{-2}$ in the compression molded GFRP-BMC panels (standard deviation in brackets). Moreover, the $a_{\mathrm{uc}}$ was increased by $27.6,19.1,29.9$ and $29.5 \%$ for each sub-quadrant A, B, $\mathrm{C}, \mathrm{D}$, respectively, demonstrating that $a_{\mathrm{uc}}$ can be raised regardless of the texture angles examined in the panel.

Table 5. Average Charpy impact values, $a_{\mathrm{uc}}$, and standard deviations for all texture angles, $\theta_{\mathrm{t}}$ cumulative (56 sample data set), and for each solidification texture angle sub-quadrant, A, B, C, and D. Standard deviations are in brackets.

\begin{tabular}{cccccc}
\hline \multicolumn{7}{c}{ Charpy Impact Values $\mathbf{( k J m}^{-2} \mathbf{)}$} \\
\hline $\begin{array}{c}\text { Fiber } \\
\text { Length }(\mathbf{m m})\end{array}$ & $\begin{array}{c}\text { Total } \\
\text { A + B + C + D }\end{array}$ & A & B & C & D \\
\hline 6.4 & $7.63(1.85)$ & $6.41(1.24)$ & $9.44(1.61)$ & $7.89(1.28)$ & $6.79(1.64)$ \\
0.44 & $9.62(2.80)$ & $8.18(2.27)$ & $11.25(2.11)$ & $10.25(3.79)$ & $8.79(1.72)$ \\
$\% \mathrm{imp}$ & 26.1 & 27.6 & 19.1 & 29.9 & 29.5 \\
\hline
\end{tabular}

Figure $4 \mathrm{a}$ shows the $P_{\mathrm{f}}$ vs. $a_{\mathrm{uc}}$ plot for all solidification texture angles, $\theta_{\mathrm{t}}$, of all individual samples of Sections A, B, C, and D, cumulatively in the two 56-specimen data sets, namely, the $6.4 \mathrm{~mm}$ and the shortened fiber $0.44 \mathrm{~mm}$ samples, respectively. At medianfracture probability, $P_{\mathrm{f}}=0.50$, therefore, shortening fibers by 30 min extended mixing improved the Charpy impact value $a_{\mathrm{uc}}$ by $29 \%$, from 7.43 to $9.59 \mathrm{kJm}^{-2}$. Moreover, at high $P_{\mathrm{f}}=0.88, a_{\mathrm{uc}}$ improved by $40 \%$, from 9.57 to $13.38 \mathrm{kJm}^{-2}$. The $a_{\mathrm{uc}}$ was improved at all $P_{\mathrm{f}}$ above 0.03 .

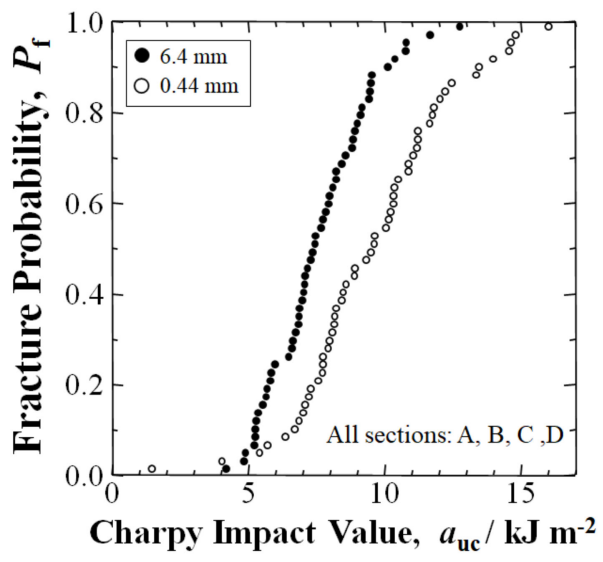

(a)

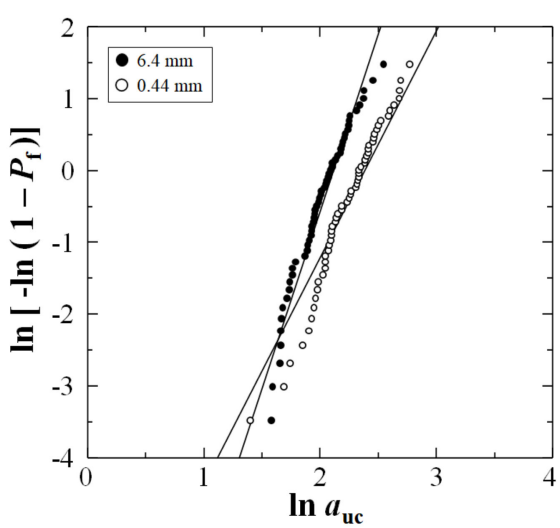

(b)

Figure 4. (a) Relationship between Charpy impact value, auc, and fracture probability, Pf, for nominal $6.4 \mathrm{~mm}$ and extended mixing $0.44 \mathrm{~mm}$ samples in a GFRP-BMC compression-molded panel, with the cumulative of Sections A, B, C and D equaling 56 samples each of the 6.4 and $0.44 \mathrm{~mm}$ fiber length sample data sets, respectively; (b) Weibull 2-parameter plots of data in (a).

\subsection{Weibull Analysis: All Texture Angles, $\theta_{t}$ Cumulative}

Weibull analysis is a standard method widely utilized to compare many structural materials [34-36]. The 2-dimensional Weibull coefficient $(n)$ is calculated from the experimental Charpy impact values $\left(a_{\mathrm{uc}}\right)$ and fracture probability $\left(P_{\mathrm{f}}\right)$, where $\left(a_{\mathrm{uc}} / a_{\mathrm{o}}\right)$ is the rupture risk [34-36]:

$$
P_{\mathrm{f}}=1-\exp \left[-\left(a_{\mathrm{uc}} / a_{\mathrm{o}}\right)^{n}\right]
$$


The linear form is [34-36]:

$$
\ln \left(-\ln \left(1-P_{\mathrm{f}}\right)\right)=n\left[\ln a_{\mathrm{uc}}-\ln a_{\mathrm{o}}\right]
$$

Figure $4 \mathrm{~b}$ shows the resulting Weibull plots for the $6.4 \mathrm{~mm}$ and $0.44 \mathrm{~mm}$ data sets, respectively, where the $n$ values are slope lines. In the $0.44 \mathrm{~mm}$ data set, although $n$ reduced from 4.92 to 3.15 , the impact values increased by $29 \%$ at a median $-P_{\mathrm{f}}$ of 0.50 , and $26 \%$ average. The $n$ was reduced due to the two weakest samples achieving below $P_{\mathrm{f}}=0.03$.

Differences in $n$ result from higher gradients of low and high fiber or filler density areas [27], i.e., an increased anisotropy within a panel or between different panels. For the $0.44 \mathrm{~mm}$ data set, the two lowest $a_{\mathrm{uc}}$ samples probably had more lower fiber density or abrupt fiber density reduction sites than the other samples, which may be an explanation for the high variance. Shortening the glass fibers by extended mixing increased the $a_{\mathrm{uc}}$ and overcame this issue.

\subsection{Optical Microscopy}

Figure $5 \mathrm{a}, \mathrm{b}$ shows photos by optical microscope of polished samples from center ASections for (a) nominal $6.4 \mathrm{~mm}$, and (b) shortened fiber formulations, respectively. Photos were taken normal to sample cross-sections as illustrated. The extended mixing formulation appears to have a significantly higher proportion of shorter fiber cross-sections with higher, more homogeneous dispersion than the nominal $6.4 \mathrm{~mm}$ commercial fibers, allowing for an increased number of spaces between fibers, $S_{\mathrm{f}}$.

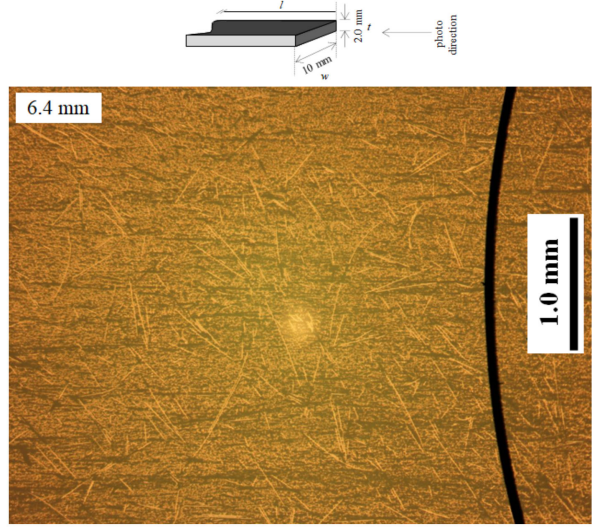

(a)

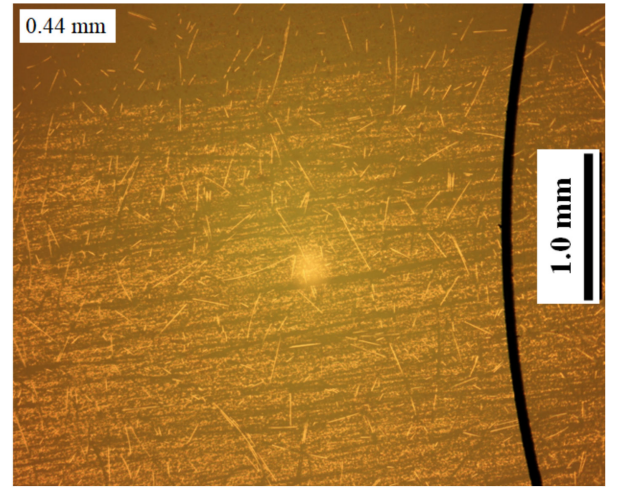

(b)

Figure 5. Optical microscope photos from center A-sections for: (a) nominal $6.4 \mathrm{~mm}$, and (b) $0.44 \mathrm{~mm}$ BMC samples, respectively, and a diagram of optical microscopy direction.

Note that the top photo of the nominal $6.4 \mathrm{~mm}$ specimen (Figure 5a) has curved long fibers probably configuring into the $2 \mathrm{~mm}$ panel thickness, which is mostly absent in the shorter fiber photo (Figure $5 b$ ).

\subsection{Effect of Shortening Fibers on Impact Strength as a Function of Texture Angle 3.4.1. $\left[\theta_{\mathrm{t}}=\right.$ Random (45) 0 to $\left.90 \mathrm{deg}\right]$ A-Section}

To show the effects of shortening fibers on the increase of impact strength according to the solidification texture angle, $\theta_{\mathrm{t}}$, between mold flow and longitudinal direction of the testing sample, sections A, B, C, D that were depicted in the $P_{\mathrm{f}}$ vs. $a_{\mathrm{uc}}$ plot of Figure 2 are examined separately in Figures 6-9, for 6.4 and $0.44 \mathrm{~mm}$ data sets, respectively. 


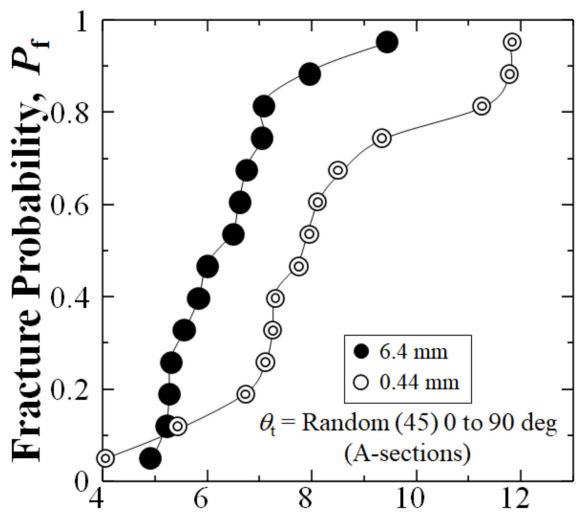

Charpy Impact Value, $a_{\mathrm{uc}} / \mathrm{kJ} \mathrm{m}^{-2}$

(a)



(b)

Figure 6. (a) Relationship between auc and Pf for nominal $6.4 \mathrm{~mm}$ and extended mixed $0.44 \mathrm{~mm}$ fiber samples, respectively, for A-Sections with $\theta \mathrm{t}$ of random (45) 0 to $90 \mathrm{deg}$ between mold flow and longitudinal direction of testing sample; (b) Weibull 2-parameter plots of data in (a).

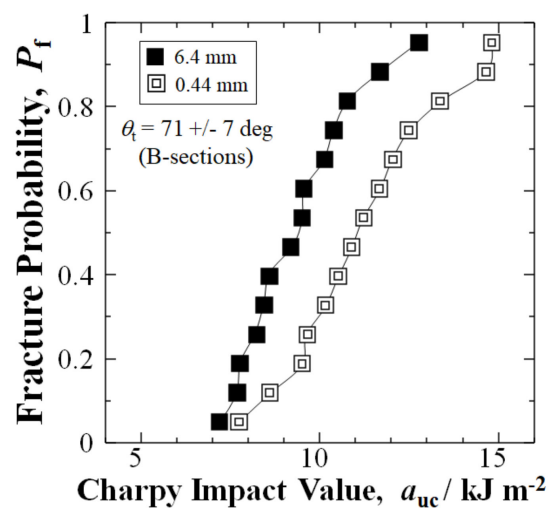

(a)

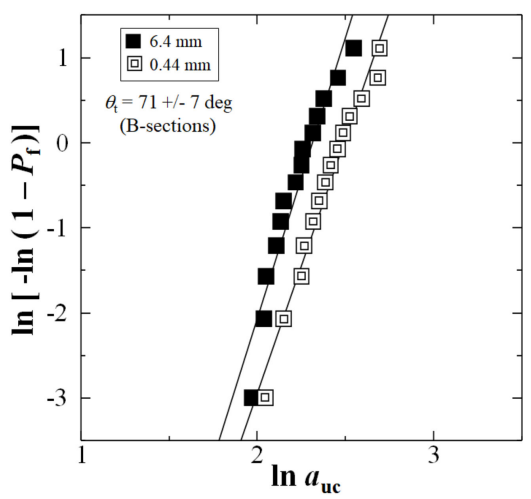

(b)

Figure 7. (a) Relationship between auc and Pf for nominal $6.4 \mathrm{~mm}$ and extended mixed $0.44 \mathrm{~mm}$ fiber samples, respectively, for B-Sections with $\theta \mathrm{t}$ of random (45) 0 to $90 \mathrm{deg}$ between mold flow and longitudinal direction of testing sample; (b) Weibull 2-parameter plots of data in (a).

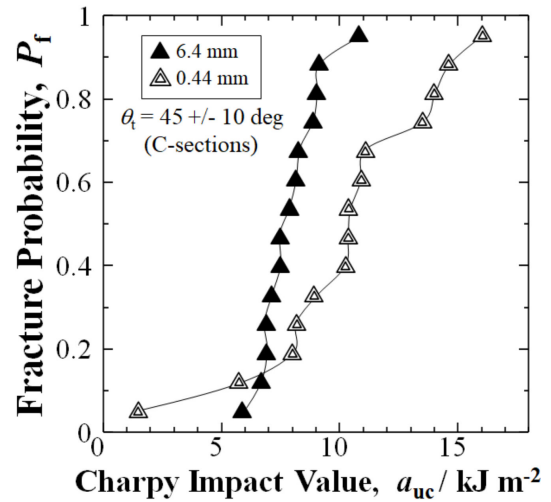

(a)

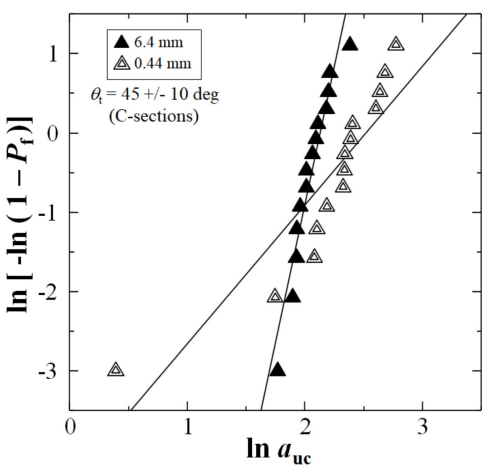

(b)

Figure 8. (a) Relationships between $a_{\mathrm{uc}}$ and $P_{\mathrm{f}}$ for nominal $6.4 \mathrm{~mm}$ and extended mixed $0.44 \mathrm{~mm}$ fiber samples, respectively, for C-Sections with $\theta_{\mathrm{t}}$ of $45+/-10$ deg between mold flow and longitudinal direction of testing sample; (b) Weibull 2-parameter plots of data in (a). 


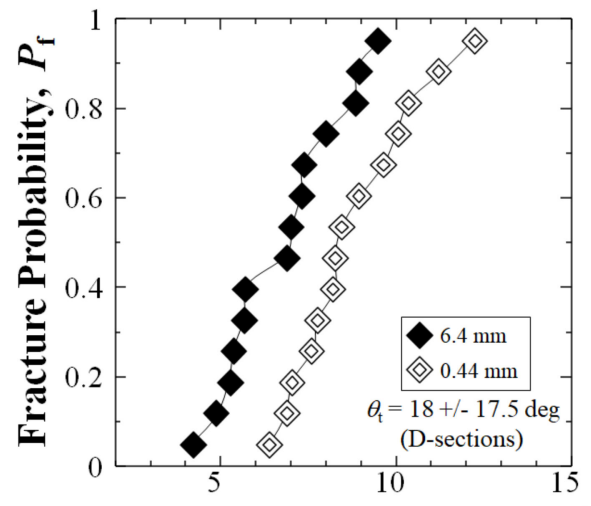

Charpy Impact Value, $a_{\mathrm{uc}} / \mathrm{kJ} \mathrm{m}^{-2}$

(a)



(b)

Figure 9. (a) Relationship between $a_{\mathrm{uc}}$ and $P_{\mathrm{f}}$ for nominal $6.4 \mathrm{~mm}$ and extended mixed $0.44 \mathrm{~mm}$ fiber sample, respectively, for D-Sections with $\theta_{\mathrm{t}}$ of $18+/-17.5 \mathrm{deg}$ between mold flow and longitudinal direction of testing sample; (b) Weibull 2-parameter plots of data in (a).

Figure 6a shows that for the typically weakest center of the GFRP panel with a texture angle of random (45) 0 to $90 \mathrm{deg}$ (A-sections) [27], shortening fibers by extended mixing improved the Charpy impact value of $a_{\mathrm{uc}}$ by $25 \%$, from 6.26 to $7.86 \mathrm{kJm}^{-2}$, at a medianfracture probability of $P_{\mathrm{f}}=0.50$. Moreover, at high $P_{\mathrm{f}}=0.88$, the $a_{\mathrm{uc}}$ improved remarkably by $48 \%$, from 7.97 to $11.79 \mathrm{kJm}^{-2}$. Figure 6 a shows that the $a_{\mathrm{uc}}$ improved at all fracture probabilities, $P_{\mathrm{f}}$, above 0.05 .

Furthermore, the extended mixing to $0.44 \mathrm{~mm}$ increased the average $a_{\mathrm{uc}}$ in A-Section by $28 \%$ over the $6.4 \mathrm{~mm}$ fiber length samples, from $6.41(1.24)$ to $8.18(2.27) \mathrm{kJm}^{-2}$. Figure $6 \mathrm{~b}$ shows that the Weibull modulus, $n$ was reduced by extended mixing from 5.81 to 3.81 , due to higher scatter in the $0.44 \mathrm{~mm}$ data set.

\subsection{2. $\left[\theta_{\mathrm{t}}=71 \pm 7 \mathrm{deg}\right]$ B-Section}

Similar to the highest solidification texture angle, with a $\theta_{\mathrm{t}}$ of $71 \pm 7 \mathrm{deg}$ (B-sections) in the GFRP panel, Figure 7a shows that shortening fibers to $0.44 \mathrm{~mm}$ by extended mixing improved the Charpy impact value $a_{\mathrm{uc}}$ by $18 \%$, from 9.36 to $11.07 \mathrm{kJm}^{-2}$, at a medianfracture probability of $P_{\mathrm{f}}=0.50$. Moreover, at high $P_{\mathrm{f}}=0.88$, the $a_{\mathrm{uc}}$ improved by $25 \%$, from 11.70 to $14.67 \mathrm{kJm}^{-2}$. Figure $7 \mathrm{a}$ shows that in B-Section the $a_{\mathrm{uc}}$ improved at all fracture probabilities, $P_{\mathrm{f}}$.

In addition, the average $a_{\mathrm{uc}}$ of $0.44 \mathrm{~mm}$ fiber length samples improved $19 \%$ above the $6.4 \mathrm{~mm}$ samples, from $9.44(1.61)$ to $11.25(2.11) \mathrm{kJm}^{-2}$. Weibull modulus, $n$, slightly decreased for B-Section, from 6.61 to 5.96, as shown in Figure 7b.

\subsection{3. $\left[\theta_{\mathrm{t}}=45 \pm 10 \mathrm{deg}\right]$ C-Section}

For the diagonal texture angle $45 \pm 10 \mathrm{deg}$ (C-sections), as shown in Figure 8a, shortening the fibers improved the $a_{\mathrm{uc}}$ by $35 \%$, from 7.68 to $10.37 \mathrm{kJm}^{-2}$ at a median-fracture probability of $P_{\mathrm{f}}=0.50$. Moreover, at high $P_{\mathrm{f}}=0.88, a_{\mathrm{uc}}$ improved remarkably by $60 \%$, from 9.14 to $14.61 \mathrm{kJm}^{-2}$.

Moreover, the average $a_{\mathrm{uc}}$ for C-Section improved by $30 \%$ over the $6.4 \mathrm{~mm}$ fiber length samples from 7.89 (1.28) to $10.25(3.79) \mathrm{kJm}^{-2}$.

The Weibull calculation in Figure $8 \mathrm{~b}$ shows the $n$ value reduced from 6.96 to 1.75, for the two weakest samples below $P_{\mathrm{f}}=0.15$. However, the $a_{\mathrm{uc}}$ increased at all $P_{\mathrm{f}}$ above 0.15 .

\subsection{4. $\left[\theta_{\mathrm{t}}=18 \pm 17.5 \mathrm{deg}\right] \mathrm{D}$-Section}

For the lowest solidification texture angle, namely, $18 \pm 17.5 \mathrm{deg}$ (D-sections), Figure 9a shows extended mixing improved the Charpy impact value $a_{\mathrm{uc}}$ by $20 \%$ over the $6.4 \mathrm{~mm}$ 
fiber length samples, from 6.96 to $8.36 \mathrm{kJm}^{-2}$ at a median- $P_{\mathrm{f}}=0.50$; and at $P_{\mathrm{f}}=0.88$, the $a_{\mathrm{uc}}$ improved by $25 \%$, from 8.95 to $11.21 \mathrm{kJm}^{-2}$. In D-Section, the $a_{\mathrm{uc}}$ improved at all fracture probabilities, $P_{\mathrm{f}}$.

Moreover, the average $a_{\mathrm{uc}}$ of D-Section improved due to extended mixing, being $29 \%$ above the $6.4 \mathrm{~mm}$ fiber length samples, from 6.79 (1.65) to 8.79 (1.72) $\mathrm{kJm}^{-2}$.

Figure $9 \mathrm{~b}$ shows that the Weibull modulus, $n$, improved slightly by extended mixing, from 4.50 to 5.76 .

Interestingly, Figures 6-9 show that the highest increase in $a_{\mathrm{uc}}$ was at a high- $P_{\mathrm{f}}$ of 0.88 for A-, B-, and C-Sections $(48,25,60 \%)$, respectively, with D-Section also showing a significant increase of $25 \%$. This could be explained by higher fiber density, $\rho_{\mathrm{f} .}$, from the flows during compression and solidification.

Comparison of the four sections A, B, C, and D themselves is considered beyond the focus of this study, due to the large existing amount of data and explanation required.

In summary, shortening glass fibers in GFRP-BMC from 6.4 to $0.44 \mathrm{~mm}$ by $30 \mathrm{~min}$ of extended mixing increased the $a_{\mathrm{uc}}$ at all solidification texture angles of $\theta_{\mathrm{t}}$ : 0 to 90 (random), 71, 45 and $18 \mathrm{deg}$ (Sections A, B, C, D); in addition to the Sections A, B, $\mathrm{C}$ and D cumulatively.

\subsection{Mechanism of Strengthening by CTE Difference}

Figure 10 illustrates the action of the CTE difference between cured polyester resin matrix (55 to $\left.100 \times 10^{-6} / \mathrm{K}\right)$ [24] and E-glass fibers $\left(5.4 \times 10^{-6} / \mathrm{K}\right)$ [25] being the thermal residual stresses generated from the matrix to the fibers during cool down and shrinkage. As fiber length is shortened, the CTE difference acts in the increased number of spaces $\left(S_{\mathrm{f}}\right)$ between fibers with closer proximity, collectively stiffening the composite and raising impact strength. To calculate the increase in $S_{\mathrm{f}}$ by shortening $6.4 \mathrm{~mm}$ fibers to $0.44 \mathrm{~mm}$, fiber density, $\rho_{\mathrm{f}}\left(\mathrm{mm}^{-3}\right)$ is calculated by the following equation [8] :

$$
\rho_{\mathrm{f}}=V_{\mathrm{f}} /\left(\pi r^{2} l_{\text {fiber }}\right)
$$

where $r$ is mean fiber radius taken to be $14 \mu \mathrm{m}(0.014 \mathrm{~mm})$, and $l_{\text {fiber }}$ is mean fiber length $(\mathrm{mm})$ [7]. This is assuming homogeneous fiber distribution and lengths. For $1 \mathrm{~mm}^{3}$ of composite, $\rho_{\mathrm{f}}$ designated $\left|\rho_{\mathrm{f}}\right|$ will equal fiber number density, $\left|N_{\mathrm{f}}\right|$ [8]:

$$
\left|\rho_{\mathrm{f}}\right|=\left|N_{\mathrm{f}}\right|=\left|S_{\mathrm{f}}\right|
$$

which in turn is equal to number of spaces: the $\left|N_{\mathrm{f}}\right|$ and $\left|S_{\mathrm{f}}\right|$ are dimensionless quantities. This would hold true for fibers oriented parallel ( $0 \mathrm{deg})$ or any angle, $\theta$, with respect to specimen length [8]. From this, $\left|S_{\mathrm{f}}\right|$ increases in order of magnitude from 217 to $2950 \mathrm{~mm}^{-3}$, increasing the impact strength of the BMC.

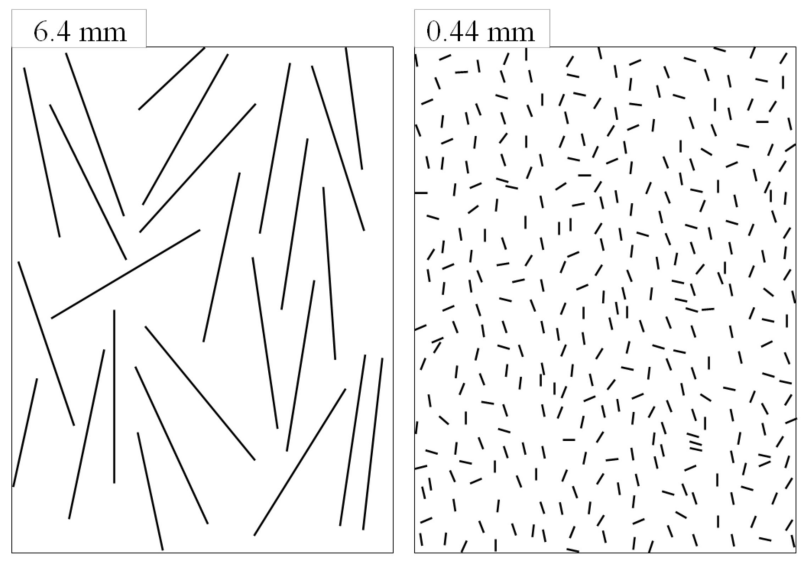

Figure 10. Schematic of increase in spaces between fibers, $S_{\mathrm{f}}$, showing closer fiber proximity. Total fiber length is illustrated as equal to represent a constant $V_{\mathrm{f}}$. 
3.6. All Texture Angles, $\theta_{t}$ Cumulative: Evaluation of Statistically Lowest Impact Value $a_{s}$ at $P_{f}=0$ Omitting 2 Lowest $a_{u c} 0.44 \mathrm{~mm}$ Samples of $P_{f}<0.03$

In compression molding, complex flow patterns can result in the creation of high- and low- fiber density areas, the low fiber density area often lowering mechanical properties [27]. Figure 11a shows in the extended mixing $0.44 \mathrm{~mm}$ data set that there were two samples out of the total of 56 with a markedly lower $a_{\mathrm{uc}}$ (dotted oval) at the lowest $P_{\mathrm{f}}<0.03$, being evidence of significantly low fiber density areas. The two samples were omitted, thereby resulting in a 54 sample data set in Figure 11b. The number of nominal $6.4 \mathrm{~mm}$ fiber length samples remained unchanged at 56. The samples omitted from the $0.44 \mathrm{~mm}$ data set were $\mathrm{C}^{\prime}{ }^{\prime}$ and $\mathrm{A} 2^{\prime}$ with an $a_{\mathrm{uc}}$ of $1.48 \mathrm{kJm}^{-2}$ and $4.06 \mathrm{kJm}^{-2}$, respectively. However, the adjoining specimens $\mathrm{C} 2^{\prime}$ and $\mathrm{A} 1^{\prime}$ had much higher $a_{\mathrm{uc}}$ at 8.19 and $9.35 \mathrm{kJm}^{-2}$, respectively, being evidence of high density gradients created during the flow and solidification of the GFRP-BMC paste.

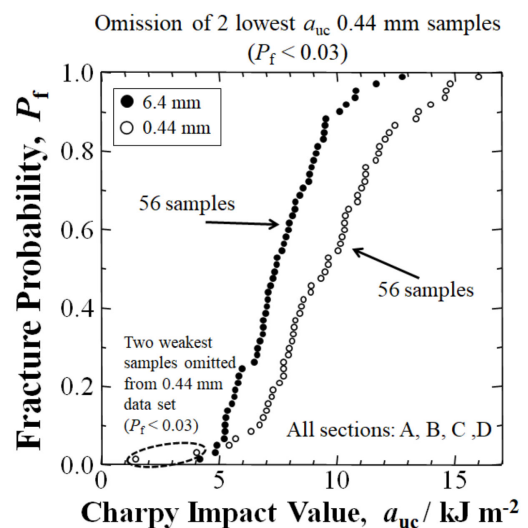

(a)



(b)

Figure 11. (a) Depiction of Figure 4a (all sections cumulative) indicating the 2 lowest $a_{\mathrm{uc}}$ samples $\left(P_{\mathrm{f}}<0.03\right)$ to be omitted from the $0.44 \mathrm{~mm}$ data set for re-evaluation. (b) Resultant graph with omission of 2 lowest $a_{\mathrm{uc}} 0.44 \mathrm{~mm}$ samples, showing relationships between $a_{\mathrm{uc}}$ and $P_{\mathrm{f}}$.

To assess safety, the statistically lowest $a_{\mathrm{s}}$ at $P_{\mathrm{f}}=0$ was calculated using 3-dimensional Weibull analysis. The $a_{\mathrm{s}}$ at $P_{\mathrm{f}}=0$ is useful for quality control (QC) of mass-produced parts. If the statistical equation is assumed to be applicable to the measured $a_{\text {uc }}$ value, the $P_{\mathrm{f}}$ depends on the risk of rupture [35,37]. In predicting the required value for a new structural material, the $a_{\mathrm{s}}$, the coefficient, $m$, and the constant, $a_{\mathrm{III}}$, are key parameters. The equation is:

$$
P_{\mathrm{f}}=1-\exp \left[-\left(\left[a_{\mathrm{uc}}-\mathrm{as}\right] / a_{\mathrm{III}}\right)^{m}\right]
$$

Rearranging in linear form yields:

$$
\ln \left(-\ln \left(1-P_{\mathrm{f}}\right)\right)=m \ln \left(a_{\mathrm{uc}}-a_{\mathrm{s}}\right)-m \ln a_{\mathrm{III}}
$$

As shown in Figure 12, when the linear form in Equation (9) is iterated for the highest correlation coefficient, $F$, the $a_{\mathrm{s}}$ is obtained. When the two lowest $a_{\mathrm{uc}}$ samples were omitted from the $0.44 \mathrm{~mm}$ data set, the $a_{\mathrm{s}}$ at $P_{\mathrm{f}}=0$ for the adjusted $0.44 \mathrm{~mm}$ sample data set $\left(4.62 \mathrm{kJm}^{-2}\right)$ was higher than the $a_{\mathrm{s}}$ of the commercial length of $6.4 \mathrm{~mm}\left(3.57 \mathrm{kJm}^{-2}\right)$, showing that an increased level of safety is possible. 


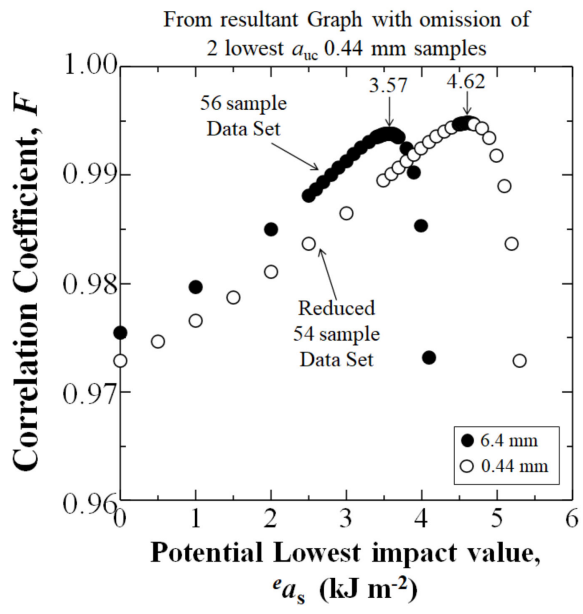

Figure 12. Iteration of potential impact value $\left({ }^{e} a_{s}\right)$ to obtain the statistically lowest impact value $a_{s}$ at $P_{\mathrm{f}}=0$ by 3-parameter Weibull analysis with the omission of the 2 lowest $a_{\mathrm{uc}} 0.44 \mathrm{~mm}$ samples for the data in Figure 11b.

\section{Conclusions}

This study demonstrates that in a highly $\mathrm{CaCO}_{3}$ filled 3-phase filler, fiber and polymer GFRP-BMC, impact strength can be increased by shortening glass fibers from the commercial fiber length of $6.4 \mathrm{~mm}(1 / 4 \mathrm{in})$ to $0.44 \mathrm{~mm}$, by $30 \mathrm{~min}$ of extended mixture of the paste prior to compression molding, without any change in compression molding equipment. This has not been previously reported in the literature, and is opposite to 2-phase fiber and polymer systems where increasing the fiber length increases the mechanical properties. The strengthening can be explained by the homogeneous distribution of increased thermal compressive stress sites induced by the increased fiber number density generated by a difference in coefficient of thermal expansion (CTE) by the matrix on the glass fibers during cooling down and shrinkage. The higher number of spaces between fibers per $\mathrm{mm}^{3},\left|S_{\mathrm{f}}\right|$, generated, is increased by an order of magnitude enhancing the impact energy. These results can be applied to maximize the safety of BMC materials through the prevention of impact damage caused by bird strike, volcanic rock, hailstones, or in space, by micrometeoroids and debris.

Author Contributions: Conceptualization, M.C.F. and Y.N.; methodology, M.C.F. and Y.N.; software, M.C.F.; validation, M.C.F. and Y.N.; formal analysis, M.C.F. and Y.N.; investigation, M.C.F. and Y.N.; resources, Y.N. and M.S.; data curation, M.C.F. and Y.N.; writing—original draft preparation, M.C.F.; writing-review and editing, M.C.F. and Y.N.; visualization, M.C.F., Y.N. and M.S.; supervision, Y.N. and M.S.; project administration, Y.N. and M.S.; funding acquisition, M.C.F., Y.N. and M.S. All authors have read and agreed to the published version of the manuscript.

Funding: This research received no external funding.

Data Availability Statement: The data presented in this study are available on request from the corresponding author. At the time the project was carried out, there was no obligation to make the data publicly available.

Acknowledgments: The authors sincerely thank Shota Iizuka M.S., of Tokai University for his great assistance with the laboratory equipment. Michael Gruskiewicz with Citadel Plastics, Conneaut, Ohio is gratefully acknowledged for providing the BMC panels.

Conflicts of Interest: The authors declare no conflict of interest. 


\section{References}

1. Faudree, M.; Baer, E.; Hiltner, A.; Collister, J. Characterization of Damage and Fracture Processes in Short Fiber BMC Composites by Acoustic Emission. J. Compos. Mater. 1988, 22, 1170-1195. [CrossRef]

2. Matykiewicz, D.; Barczewski, M.; Sterzyński, T. Morphology and thermomechanical properties of epoxy composites highly filled with waste bulk molding compounds (BMC). J. Polym. Eng. 2015, 35, 805-811. [CrossRef]

3. DeRosa, R.; Telfeyan, E.; Gaustad, G.; Mayes, S. Strength and Microscopic Investigation of Unsaturated Polyester BMC Reinforced with SMC-Recyclate. J. Thermoplast. Compos. Mater. 2005, 18, 333-349. [CrossRef]

4. Rajaee, P.; Ghasemi, F.A.; Fasihi, M.; Saberian, M. Experimental Analysis and Optimization of Mechanical and Physical Properties of Light-Weight Bulk Molding Compound by Design of Experiment. J. Macromol. Sci. Part B 2021, 60, 237-256. [CrossRef]

5. Lee, T.; Jeong, K.; Kim, D. Development of a lightweight BMC material using fly ash. Adv. Compos. Mater. 2017, 26, 55-64. [CrossRef]

6. Faudree, M.; Nishi, Y.; Gruskiewicz, M. Characterization of velocity profile of highly-filled GFRP-BMC through rectangular-duct shaped specimen during injection molding from SEM fiber orientation mapping. Mater. Trans. 2013, 54, 1877-1883. [CrossRef]

7. Faudree, M.C.; Nishi, Y. Tensile Strength Enhancement by Shortening Glass Fibers with Sub-Millimeter Length in Bulk Molding Polymer Compound. Mater. Trans. 2010, 51, 2304-2310. [CrossRef]

8. Faudree, M.C.; Nishi, Y.; Gruskiewicz, M. A Novel 'Fiber Spacing' Model of Tensile Modulus Enhancement by Shortening Fibers to Sub-Millimeter in an Injection-Molded Glass Fiber Reinforced Polymer Bulk Molding Compound (GFRP-BMC). Mater. Trans. 2014, 55, 1292-1298. [CrossRef]

9. Singh, H.; Singh, T. Effect of fillers of various sizes on mechanical characterization of natural fiber polymer hybrid composites: A review. Mater. Today Proc. 2019, 18, 5345-5350. [CrossRef]

10. Rajaee, P.; Ghasemi, F.A.; Fasihi, M.; Saberian, M. Effect of styrene-butadiene rubber and fumed silica nano-filler on the microstructure and mechanical properties of glass fiber reinforced unsaturated polyester resin. Compos. Part B Eng. 2019, 173, 106803. [CrossRef]

11. Thomason, J.L.; Vlug, M.A. Influence on fibre length and concentration on the properties of glass fibre reinforced polypropylene: 1. Tensile and flexural modulus. Compos. Part A Appl. Sci. Manuf. 1996, 27, 477-484. [CrossRef]

12. Thomason, J. The influence of fibre length, diameter and concentration on the modulus of glass fibre reinforced polyamide 6,6 . Compos. Part A Appl. Sci. Manuf. 2008, 39, 1732-1738. [CrossRef]

13. Thomason, J.L.; Vlug, M.A. Influence on fibre length and concentration on the properties of glass-fibre-reinforced polypropylene: 4. Impact properties. J. Compos Part A 1997, 28, 277-278. [CrossRef]

14. Fu, S.-Y.; Lauke, B. Effects of fiber length and fiber orientation distributions on the tensile strength of short fiber reinforced polymers. Compos. Sci. Technol. 1996, 56, 1179-1190. [CrossRef]

15. Huang, H.; Talreja, R. Numerical simulation of matrix micro-cracking in short fiber reinforced polymer composites: Initiation and propagation. Compos. Sci. Technol. 2006, 66, 2743-2757. [CrossRef]

16. Thomason, J.L. The influence of fibre properties of the performance of glass fiber reinforced polyamide 6,6. Compos. Sci. Technol. 1999, 59, 2315-2328. [CrossRef]

17. Rezaei, F.; Yunus, R.; Ibrahim, N.A.; Mahdi, E.S. Effect of fiber loading and fiber length on mechanical and thermal properties of short carbon fiber reinforced polypropylene composite. Malays. J. Anal. Sci. 2007, 11, 181-188.

18. Maertens, R.; Hees, A.; Schöttl, L.; Liebig, W.; Elsner, P.; Weidenmann, K.A. Fiber shortening during injection molding of glass fiber-reinforced phenolic molding compounds: Fiber length measurement method development and validation. Polym. Technol. Mater. 2021, 60, 872-885. [CrossRef]

19. Capela, C.; Oliveira, S.; Pestana, J.; Ferreira, J. Effect of fiber length on the mechanical properties of high dosage carbon reinforced. Procedia Struct. Integr. 2017, 5, 539-546. [CrossRef]

20. Haghighatnia, T.; Abbasian, A.; Morshedianc, J. Hemp fiber reinforced thermoplastic polyurethane composite: An investigation in mechanical properties. Ind. Crops Prod. 2017, 108, 853-863. [CrossRef]

21. Seol, K.; Krawitz, A.; Richardson, J.; Weisbrook, C. Effects of WC size and amount on the thermal residual stress in WC-Ni composites. Mater. Sci. Eng. A 2005, 398, 15-21. [CrossRef]

22. Niihara, K. Overcoming the fragility of ceramics (Challenge to strengthen ceramics). Ceram. Kyoujinka Fract. Toughness Ceram. 1986, 21, 581-589. (In Japanese)

23. Wu, C.; Shen, S.; Li, Y.; Luo, G.; Shen, Q.; Gan, Z.; Liu, J. Influence of coarse grain particles on mechanical properties and fracture behavior in multi-modal Al-based metal matrix composites. Powder Technol. 2021, 394, 901-908. [CrossRef]

24. Starink, M.; Syngellakis, S. Shear lag models for discontinuous composites: Fibre end stresses and weak interface layers. Mater. Sci. Eng. A 1999, 270, 270-277. [CrossRef]

25. Bauccio, M.L. (Ed.) ASM Engineered Materials Reference Book, 2nd ed.; ASM International: Novelty, OH, USA, 1994.

26. Dragoi, D.; Üstündag, E.; Clausen, B.; Bourke, M.A. Investigation of thermal residual stresses in tungsten-fiber/bulk metallic glass matrix composites. Scr. Mater. 2001, 45, 245-252. [CrossRef]

27. Faudree, M.; Nishi, Y.; Gruskiewicz, M. Effects of electron beam irradiation on Charpy impact value of short glass fiber (GFRP) samples with random distribution of solidification texture angles from zero to 90 degrees. Mater. Trans. 2012, 53, 1412-2310. [CrossRef] 
28. Faudree, M.; Nishi, Y.; Gruskiewicz, M.; Salvia, M. A new glass fibered reinforced composite with improved Charpy impact properties at low and high temperatures beyond the extremes of aircraft flight. Mater. Trans. 2018, 59, 1280-1287. [CrossRef]

29. ASTM D 6110-02; Standard test methods for determining the Charpy impact resistance of notched specimens of plastics. American Society for Testing and Materials: West Conshohocken, PA, USA, 2002.

30. JIS K 7077; Testing method for Charpy impact strength of carbon fiber reinforced plastics. Japanese Industrial Standards Committee: Tokyo, Japan, 1991. (In Japanese)

31. Nishi, Y.; Inoue, K.; Salvia, M. Improvement of Charpy Impact of Carbon Fiber Reinforced Polymer by Low Energy Sheet Electron Beam Irradiation. Mater. Trans. 2006, 47, 2846-2851. [CrossRef]

32. Splett, J.; Iyer, H.; Wang, C.; McCowan, C. National Institute of Standards and Technology (NIST) Recommended Practice Guide, Computing Uncertainty for Charpy Impact Test Machine Test Results; Special publication 960-18; US Department of Commerce: Boulder, CO, USA, 2008; pp. 27-29.

33. Nishida, T.; Yasuda, E. Evaluation of Dynamic Properties of Ceramics (In Japanese, Ceramics No Rikigaku Tokusei Hyouka); Nikkan Kogaku Shimbun Sha: Tokyo, Japan, 1986; pp. 50-51. (In Japanese)

34. Weibull, W. A Statistical Theory of the Strength of Materials; Ingeniörs vetenskaps akademien; nr. 151; (Generalstabens litografiska anstalts förlag); Engineer Science Academy, Lithographic Institution Publisher: Stockholm, Sweden, 1939; pp. 12-14.

35. Weibull, W. A Statistical Theory of the Strength of Materials; Ingeniörs vetenskaps akademien; nr. 153; (Generalstabens litografiska anstalts förlag); Engineer Science Academy, Lithographic Institution Publisher: Stockholm, Sweden, 1939; pp. 16-22.

36. Quinn, J.B.; Quinn, G.D. A practical and systematic review of Weibull statistics for reporting strengths of dental materials. Dent. Mater. 2010, 26, 135-147. [CrossRef]

37. Nishi, Y.; Kobayashi, H.; Salvia, M. Effects of Electron Beam Irradiation on Charpy Impact Value of GFRP. Mater. Trans. 2007, 48, 1924-1927. [CrossRef] 